\title{
Modifying the IAT to test the relationship between Actual Implicit Self Esteem and depression - A preliminary analysis
}

\author{
Nastasia Sălăgean ${ }^{1}$ \\ ${ }^{1}$ Department of Psychology, West University Timişoara, Romania
}

Received 10.03.2017; Received revised 18.05.2017; Accepted 10.06.2017

Available online 30.06.2017

\begin{abstract}
This paper sought to test weather modifying the Implicit Association Test (IAT) to contextualize it would better predict depressive symptoms, compared to the classical IAT. Additionally, we explored how both versions of the IAT interact with explicit measures of self-esteem. Using a total of 99 university students ( $75.75 \%$ female), we collected measures of implicit self-esteem (IAT; Greenwald, McGhee, \& Schwartz, 1998), actual implicit self-esteem (modified IAT), explicit selfesteem (ESE; Rosenberg,1965), and depression (Spitzer et al, 1999). The same data was collected again after 2 weeks. After employing several hierarchical stepwise regression analyses, results show that the only valid predictor for depression is ESE, with both IAT measurements failing to provide significant results. However, a significant relationship between depression at Time 1 were associated with both standard ISE at Time $2(r=-0.24, \mathrm{p}<.05)$ and actual ISE at Time $2(r=-0.28$, $\mathrm{p}<.05)$. No interaction effects were found between either IAT measure and ESE in predicting selfesteem. Moreover, no significant correlations were found between either type of ISE and ESE. The implications of the study are discussed.
\end{abstract}

Keywords: Implicit self-esteem, IAT, Actual Self-Esteem, Depression, Students.

Address of correspondence: Nastasia Sălăgean, West University, Bld. V. Pârvan nr. 4, Timișoara, 300233, Romania.

E-mail: nastasia.salagean@e-uvt.ro

\section{Introduction}

Depression is perhaps one of the most widespread mental diseases, both in adults (Parikh \& Lam, 2001; Kessler, Berglund, Demler, Jin, \& Walters, 2005) and in young adults (Wittchen, Nelson \& Lachner, 1998). Moreover, it has a high economic burden (Sobocki, Jönsson, Angst \& Rehnberg, 2006), and has a relatively high recurrence rate (Hardeveld, Spijker, De Graaf, Nolen \& Beekman, 2013). Symptoms of depression limit work productivity, reduce social interactions and produce an overall sense of impairment in over $90 \%$ of those with recurrent depression (Wittchen, Nelson \& Lachner, 1998). Therefore, if we seek to reduce symptoms of depression, understanding what predicts its development and how to measure these factors is crucial.

One concept that seems to be heavily involved in depression is self-esteem as it is viewed as the global attitude that one has toward the self (Rosenberg, 1965). Currently, we can distinguish between two types of selfesteem, as per the dual process models: an automatic, nonconscious assessment of the self, known as implicit self-esteem (ISE) and a deliberate, conscious evaluation of the self, known as explicit self-esteem (ESE) (Boson, Swann \& Pennebaker, 2000).

The difference between the two is not purely semantic, but rather is rooted in the fact that ISE is generally weakly correlated with ESE (Hofmann, Gawronski, Gschwendner, Le \& Schmitt, 2005), suggesting that they are independent concepts. Moreover, while the relationship between ESE and depression symptoms has received much attention, with ESE being an established predictor of depression (see Sowislo \& Orth, 2013), the same cannot be said for ISE. Some studies suggest the existence of a significant, medium-sized correlation between the two (Creemers, Sholte, Engels, Prinstein \& Wiers, 2013; De Raedt, Schacht, Franck \& De Houwer, 2006; Steinberg, Karpinski \& Alloy, 2007) while others found no correlation between ISE and depression (de Jong, Sportel, de Hullu \& Nauta, 2012; Haeffel, Abramson, Brazy, Shah, Teachman \& Nosek, 2007). Moreover, some studies seem to find a similar (positive) association with ISE in both depressed and non-depressed samples (De Raedt et al., 2006).

Remue et al. (2013) hypothesize that the reason behind these sometimes-confusing results is due to the fact that the ISE is divided into two distinct concepts: a) an actual ISE, referring to the attributes a person believes to currently 
hold (i.e. "I am" and "positive"); and b) and ideal selfesteem, which encompasses the characteristics a person would like to possess (i.e. "I want to be" and "positive"). Since ISE measures traditionally test the association of the self with positive or negative attributes (i.e. "I" and "positive"), devoid of any context to discern between desirability and actuality, it is impossible to tell which of the two types of ISE is being measured, hence the contradictory results.

The differentiation seems to be supported by initial research. For example, the results of Remue et al. (2013) indicate that actual self-esteem is lower and ideal selfesteem is higher in dysphorics compared non-dysphorics. Additionally, Remue, Hughes, De Hower and De Raedt (2014), found that dysphorics tended to have a higher discrepancy between ideal self-esteem and actual selfesteem when compared to non-dysphorics. Both studies seem to suggest that the actual self-esteem is a better predictor of current depression, but neither study has studied if the actual self-esteem is a predictor of future depression. It should be noted however that presently, only two papers have been published on this subject, with both using a relatively novel measure of ISE: the Implicit Relational Assessment Procedure (IRAP; Barnes-Holmes, Barnes-Holmes, Power, Milne \& Stewart, 2006).

\section{IRAP versus IAT}

The Implicit Association Test (IAT; Greenwald, McGhee, \& Schwartz, 1998) is perhaps the most widespread measure of implicit beliefs or attitudes. Following the principle laid out by Greenwald et al (1998), the Self-Worth IAT (Greenwald and Farnham, 2000) was designed to measure the association between a targetconcept (i.e. "me"/ "non-me") and an attribute dimension (i.e. ("positive"/negative"), based on the idea that reaction times would be faster when two concepts share a single response if those concepts are associated in memory than when the concepts are unrelated. Subjects must categorize each stimulus presented on the screen as quickly and as accurately as possible in one of the categories. Depending on the condition (compatible / incompatible), subjects must first either a) use the same key to sort "me" and positive stimuli and a separate key for negative and "others" stimuli (compatible block) or b) must sort pleasant and "others" stimuli using a key and unpleasant and "me" stimuli using a different key (incompatible block). In future blocks the order is then reversed.

Perugini and colleagues (2012) recommend that the stimuli used in the IAT should be pre-tested prior to the actual conducting of the test. Barnes-Holmes et al (2006) proposed the IRAP, believing that the context and individual's history with the stimuli is superior to how the two stimuli are associated in memory. The IRAP requires participants to respond to a set of prior developed stimulus relations by forcing them to respond consistent (e.i., "I am good" + True) or inconsistent (e.i., "I am good" + False) with their beliefs. The IRAP proposes that participants would answer more quickly in trials where there is a congruency between the respondent's internal beliefs and the required outcome, when compared with trials where the two are incongruent.

One of the proposed issues with the classical IAT is that it measures the relative association between the target and the attribute, and as such only shows that someone has a more positive/negative association with himself than with 'others', but can't indicate the strength of these associations (Roefs et al., 2011). In the self-esteem IRAP this issue is somewhat addressed, by changing the comparison target category (in this case "Others"), to the negative of the studied target category (i.e. "Not me"). Other measures of implicit self-esteem have tried to eliminate the contrast category as well. Notably, Lemmens and colleagues (2014) used a modified version of the IAT, named SingleCategory IAT (SC-IAT), to see whether currently depressed individuals showed any significant differences in ISE, but to no avail. Similarly, Steinberg (2006) looked at the association between standard ISE as measured by the SC-IAT and depression, but the results were insignificant and had a negligible effect size $(r=0.02, \mathrm{p}>0.05)$. Additionally, the IRAP seems to be unreliable, both in terms of internal consistency and in terms of test-retest reliability.

Banking on the fact that the IAT produces more reliable results, especially when compared to other implicit measures (Bar-Anan \& Nosek, 2014), the present study attempts to partially replicate Remue et al's (2013) results, but with using the IAT. Should the difference between standard and actual ISE be down to the fact that latter measures the evaluation of the current self and not the global evaluation of the self in general (regardless of context), and not on the characteristics of the IRAP, it would stand to reason that by simply modifying the existing IAT to focus participant's attention on their present believed value would be sufficient to repeat the results found in previous studies.

More precisely, we wanted to see if, by modifying the target stimuli of the IAT to specifically target actual selfesteem, we would better predict current and future depressive symptoms than when compared to the classic IAT, and if they added anything to the current ESE predictive model.

Additionally, we also wanted to explore if and how the modified version of the IAT would interact with explicit measures of self-esteem, since research seems to suggest that there should be little to no overlap between the two (Hofmann et al, 2005; Remue et al, 2014). Should the developed measure be truly implicit, we would expect the results to concur with current literature. On a similar reasoning, we also expect there to be a weak positive correlation between the standard ISE (as measured by the classic IAT) and the actual ISE (as measured by the modified IAT).

\section{Method}

\section{Participants}

One hundred and one students at the West University of Timişoara were recruited through an online advertisement on the university's group discussion lists. Students received course credit for participating in the study. All participants completed the first session of the data collection in late November 2016. A total of 99 students (75 females) returned for the second session which was held approximately two weeks after the first session. Participants' age in the final sample ranged from 18 to $47(\mathrm{M}=23.09, \mathrm{SD}=6.66)$.

\section{Measures}

Rosenberg's Scale of Self-esteem (Rosenberg, 1965) was used to assess ESE. The scale consists of ten items on a four-point scale, ranging from strongly disagree (1) to strongly agree (4). Higher scores indicate a high level of explicit self-esteem. The internal consistency was high 
both at Time $1(\alpha=.88)$, and at Time $2(\alpha=.87)$, and testretest reliability was also high $(.85)$.

We used a version of the Implicit Association Test (Greenwald and Farnham, 2000; Greenwald, McGhee and Schwartz, 1998) to measure the standard ISE. Participants had to categorize as quickly and as accurately as possible target stimuli (i.e. "me" or "others/non-me".) and attribute stimuli (positive/negative). Five "me" (I, me, mine, self, mine) and five "non-me" (others, the other, them-male, them-female, theirs) pronouns served as target stimuli. Six positive (confident, determined, ambitious, courageous, optimist, and strong) and six negative Romanian adjectives (abandoned, loser, inferior, unsure, disappointing and mistrustful) served as attribute stimuli. To ensure the best compatibility with self-esteem, the stimuli were tested prior to the beginning of the study on 64 volunteers. Since adjectives in Romanian have a different feminine and masculine form, we used separate IATs for females and males. There were no observed differences between the "classic" IATs based on gender either at Time 1 or at Time 2. Each participant completed seven blocks of trials. During the first block (20 trials), participants practiced categorizing stimuli from the two target categories. In the second block (20 trials) participants practiced categorizing stimuli based on valence. In block 3 (20 trials) participants practiced sorting combined target and attribute stimuli to their respective categories. The forth block (40 trials) was the same as the third. The fifth block ( 20 trials) reversed the key assignments for self- and other-related items. Finally, the sixth block (20 trials) and seventh block (40 trials) merged the switch of the self and other-related items in the fifth block with the combination of target and attribute stimuli found in the third and fourth block. The order of the critical test blocks was counterbalanced across participants. The difference between the fourth and seventh test blocks was computed using the algorithm described by Greenwald, Nosek and Banaji (2003). Higher scores indicate higher levels of implicit self-esteem. Split-half reliability for internal consistency was low both at Time 1 (.32) and at Time 2 (.35). Test-retest reliability was also quite low (.30), but this is not unusual, as it has been found to range between .25 and .69 (Lane, Banaji, Nosek \& Greenwald, 2007).

We used a modified version the IAT presented earlier to measure actual ISE. The only difference between the two measures consists in the selected target stimuli. Therefore, instead of using pronouns, we used 5 selfrelated statements (I am; I see myself; I believe I am; I consider myself; I think $I$ am) and 5 other-related statements (They are; They see themselves; They believe they are; They think they are; They consider themselves). Higher scores indicate higher levels of implicit self-esteem. Split-half reliability for internal consistency was low both at Time 1 (.31) and at Time 2 (.37). Test-retest reliability was also very low (.14).

Depression was measured using the Patient Health Questionnaire (PHQ-9; Spitzer et al, 1999). The scale measures the presence of depressive symptoms in the last two weeks using 9 Likert-type items, with answers ranging from "Not at all" (0) to "Nearly every day" (3). Higher scores indicate a high level of depression. The internal consistency was adequate both at Time $1(\alpha=.80)$, and at Time $2(\alpha=.79)$, and test-retest reliability at two weeks was also adequate (.62).

\section{Procedure}

All measures were completed in group testing rooms at both measurement points. After giving their informed consent, participants first completed the implicit measures and then the explicit measures. The implicit measures were counterbalanced both within and between sessions. All measures were computerized.

\section{Results}

Descriptive statistics and correlations between the study's variables are presented in Table 1 . Preliminary data seems to suggest that, apart from the relationship between depression at Time 1 and both standard ISE and actual ISE at Time 2, no significant results between ISE and depression were found. Moreover, the standard ISE at Time 1 correlates with the actual ISE at Time $2(r=.25, \mathrm{p}<$ $.05)$ but not with the actual ISE at Time 1. Interestingly, the standard ISE at Time 2 correlates with actual ISE at Time $2(r=.43, \mathrm{p}<.01)$.

We used hierarchical stepwise regression analysis to test the relationship between standard ISE and ESE on predicting depression, as well as to test their interactive effect. We first transformed the raw scores of explicit and ISE into standardized z-scores, and then we computed the cross-product vector of these two standardized variables. These three variables were predictors in the regression analysis. The results are presented in Table 2 . The results show an independent relationship between standard ISE at Time 1 and both current $\left(\mathrm{b}=-0.16, \mathrm{SE}_{\mathrm{b}}=-0.44, \beta=0.10, \mathrm{p}\right.$ $=0.28)$ and future depression $\left(\mathrm{b}=-0.65, \mathrm{SE}_{\mathrm{b}}=1.27, \beta=\right.$ $0.05, \mathrm{p}=0.61$ ), with ESE being the only accurate predictors for depression at Time $1\left(\mathrm{~b}=-0.43, \mathrm{SE}_{\mathrm{b}}=-0.09\right.$ $\beta=-0.47, p=0.000)$ and Time $2\left(b=-2.21, \mathrm{SE}_{\mathrm{b}}=-0.28 \beta\right.$ $=-0.04, \mathrm{p}=0.000)$. Moreover, the interaction between ESE and standard ISE was not found to be statistically significant neither at Time $1\left(\mathrm{~b}=-0.60, \mathrm{SE}_{\mathrm{b}}=0.40, \beta=\right.$ $0.13, \mathrm{p}=0.14)$ nor at Time $2\left(\mathrm{~b}=-0.50, \mathrm{SE}_{\mathrm{b}}=0.40, \beta=\right.$ $0.12, \mathrm{p}=0.21)$.attitudes $(F(1,78)=1.705, p=019$, partial $\left.\eta^{2}=.021\right)$.

We again employed hierarchical stepwise regression analysis to test the relationship between actual ISE and ESE on predicting depression, using the procedure described above. The results are presented in Table 3 . Similar to the previous findings, we found insignificant results for Actual ISE in predicting depression both at Time $1\left(\mathrm{~b}=-0.44, \mathrm{SE}_{\mathrm{b}}=0.40, \beta=-0.10, \mathrm{p}=0.28\right)$ and at Time $2\left(\mathrm{~b}=-1.75, \mathrm{SE}_{\mathrm{b}}=1.28, \beta=-0.13, \mathrm{p}=0.18\right)$. Again, only the ESE seems to be a valid predictor for current $(\mathrm{b}=$ -2.37, $\left.\mathrm{SE}_{\mathrm{b}}=0.40, \beta=-0.52, \mathrm{p}=0.000\right)$ and future depression $\left(b=-0.43, \mathrm{SE}_{\mathrm{b}}=0.09, \beta=-0.47, \mathrm{p}=0.000\right)$, and the interaction between actual ISE and ESE is not significant in either instances $\left(b=0.12, \mathrm{SE}_{\mathrm{b}}=0.37, \beta=\right.$ $0.03, p=0.75 ; b=0.25, \mathrm{SE}_{\mathrm{b}}=0.26, \beta=0.63, \mathrm{p}=0.49$ ). 
Table 1. Descriptive statistics and intercorrelations of the studied variables

\begin{tabular}{|c|c|c|c|c|c|c|c|c|c|c|}
\hline Variable & Mean & $S D$ & 1 & 2 & 3 & 4 & 5 & 6 & 7 & 8 \\
\hline ISE 1 & .48 & .31 & 1 & & & & & & & \\
\hline ISE 2 & .40 & .32 & $.31 * *$ & 1 & & & & & & \\
\hline Actual ISE 1 & .46 & .31 & -.03 & .06 & 1 & & & & & \\
\hline Actual ISE 2 & .37 & .33 & $.25^{*}$ & $.43^{* *}$ & .14 & 1 & & & & \\
\hline PHQ-9 1 & 7.06 & 4.58 & -.15 & $-.28 * *$ & -.16 & $-.24 *$ & 1 & & & \\
\hline PHQ-9 2 & 6.21 & 4.31 & -.12 & -.12 & -.19 & -.19 & $.62 * *$ & 1 & & \\
\hline ESE 1 & 30.40 & 4.71 & .14 & .17 & .12 & .18 & $-.53 * *$ & $-.46 * *$ & 1 & \\
\hline ESE 2 & 30.82 & 5.02 & .10 & .14 & .11 & .09 & $-.57 * *$ & $-.54 * *$ & $.85 * *$ & 1 \\
\hline
\end{tabular}

Notes: $\mathrm{N}=99 ; *$ correlation is significant at $\mathrm{p}<.05 ; * *$ correlation is significant at $\mathrm{p}<.01$.

Table 2. Results of the regression analysis conducted using standard ISE and ESE

\begin{tabular}{|c|c|c|c|c|c|c|}
\hline & \multicolumn{3}{|c|}{ Depression at Time 1} & \multicolumn{3}{|c|}{ Depression at Time 2} \\
\hline & $\beta$ & $R^{2}$ & $\Delta R^{2}$ & $\beta$ & $R^{2}$ & $\Delta R^{2}$ \\
\hline Step one & \multicolumn{3}{|c|}{.29} & \multicolumn{3}{|c|}{.21} \\
\hline ISE at Time $1 /$ Time 2 & -.12 & & & -.06 & & \\
\hline ESE at Time 1 / Time 2 & $-.52 *$ & & & $-.45^{*}$ & & \\
\hline Step two & & .31 & $.016, \mathrm{~ns}$ & & .23 & $.013, \mathrm{~ns}$ \\
\hline ISE at Time 1 / Time 2 & -.10 & & & -.05 & & \\
\hline ESE at Time $1 /$ Time 2 & $-.54 *$ & & & $-.47 *$ & & \\
\hline ISE at Time $1 /$ Time $2 \mathrm{X}$ & -.13 & & & -.12 & & \\
\hline ESE at Time $1 /$ Time 2 & & & & & & \\
\hline
\end{tabular}

Notes: * correlation is significant at $\mathrm{p}<.001$.

Table 3. Results of the regression analysis conducted using actual ISE and ESE

\begin{tabular}{|c|c|c|c|c|c|c|}
\hline & \multicolumn{3}{|c|}{ Depression at Time 1} & \multicolumn{3}{|c|}{ Depression at Time 2} \\
\hline & $\beta$ & $R^{2}$ & $\Delta R^{2}$ & $\beta$ & $R^{2}$ & $\Delta R^{2}$ \\
\hline Step one & & .29 & & & .226 & \\
\hline Actual ISE at Time 1 / Time 2 & -.10 & & & -.13 & & \\
\hline ESE at Time 1 / Time 2 & $-.52 *$ & & & $-.44 *$ & & \\
\hline Step two & & .291 & $.001, \mathrm{~ns}$ & & .23 & $.004, \mathrm{~ns}$ \\
\hline Actual ISE at Time 1 / Time 2 & -.09 & & & -.13 & & \\
\hline ESE at Time 1 / Time 2 & $-.52 *$ & & & $-.44 *$ & & \\
\hline $\begin{array}{l}\text { Actual ISE at Time } 1 \text { / Time } 2 \\
\text { X ESE at Time } 1 \text { / Time } 2\end{array}$ & .03 & & & .06 & & \\
\hline
\end{tabular}

Notes: * correlation is significant at $\mathrm{p}<.001$

\section{Discussion}

The objective of this study was to examine whether scores on actual ISE and ESE predict current and future depressive symptoms. Furthermore, we tested whether this new actual ISE is better at predicting depressive symptoms than the standard ISE. We also examined whether the interaction between either actual ISE or standard ISE, and ESE further predicted symptoms of depression. Explicit self-esteem was hypothesized to be positively and low to moderately associated with both types of ISE measures.

Since most of our results proved to be insignificant, it is challenging to accurately interpret the possible reasons behind these results. We can only hypothesize as to the possible explanations, and hope that further research addresses these issues.

A possible reason for why both the classical and the modified version of the IAT failed to predict both current and future depression has to do with the target categories used in this study. Traditionally, the classical IAT measures the relative association between the target and the attribute, while in the IRAP this issue is somewhat addressed by changing the comparison target category (in this case "Others"), to the negative of the studied target category (i.e. "Not me"). In the present study, we used the traditional category labels with both the classic IAT and the modified IAT, even though the stimuli were different.
It must also be noted though that the IRAP uses only two target stimuli, one for each category, while the IAT traditionally uses 10 such stimuli, which could also be one of the reasons why the results were insignificant compared with the original studies.

It could also be argued that performance on the IRAP provides an implicit measure of the propositional (explicit) system, while the results on the IAT are the implicit measure of the associative (implicit) system, which could be one of the reasons why we failed to replicate the previous significant results. Some studies (Gawronski \& Bodenhausen, 2006, 2007, and 2011) propose that while associations can be activated regardless of the accuracy of the information, propositional (explicit) processes are by nature focused on the truth. As per the associativepropositional evaluation model (APE, Gawronski \& Bodenhausen, 2006), both the pre-existing structure of associations stored in memory and the general set of stimuli influence the associations that will be activated (Gawronski \& Bodenhausen, 2011). Thus, the activation process is not dichotomous or "all or nothing" but rather the stimuli activates a limited number of associations regarding the stimuli, depending on the situation. As such, different associations can be activated by the same stimuli in distinct situations. The fact that the classical IAT measure at Time 2 correlates moderately with the modified IAT at Time $2(r=-0.43, \mathrm{p}<.05)$ is a bit worrying, since it would suggest that they measure the same construct. 
With regards to the relationship between the ESE and the two IAT measures, one possible reason as to why we failed to find any significant correlations or interactions, both at Time 1 and at Time 2 has to do with the fact that the two predict different outcomes and rely independent systems (Franck, De Raedt, Jan \& De Houwer, 2007). This result is indeed surprising, as most literature suggests that there should be some form of interaction, however low it may be (Hofmann, Gawronski, Gschwendner, Le \& Schmitt, 2005). More likely though is the fact that the low reliability of the implicit measures may have affected the already weak correlations with ESE.

The abysmal test-retest reliability (.14) may work in the actual ISE measure's favor, suggesting it is more statedependent rather than a trait. As Golijani-Moghaddam, Hart and Dawson (2012) suggest, if the measure is significantly context-dependent it may offer a practical utility should further research target susceptibility to change rather than consistency across administrations.

Puzzlingly, we found a significant relationship between depression at Time 1 were associated with both standard ISE at Time $2(r=-0.24, \mathrm{p}<.05)$ and actual ISE at Time 2 $(r=-0.28, \mathrm{p}<.05)$. This result may suggest that rather than the cognitive vulnerability model (Beck \& Haigh, 2014), where low implicit self-esteem causes depressive symptoms, perhaps, with regards to ISE, the Scar Model may help explain these results (Coyne, Gallo, Klinkman \& Calarco, 1998 apud Sowislo \& Orth, 2013). The Scar Model reverses the causality of the relationship between self-esteem and depression, suggesting that depressive symptoms are the ones to erode the self-esteem, scarring it in time. Thus, self-esteem is viewed as being a symptom of depression, rather than a cause.

Finally, since we used the same measure (even though the stimuli were different and even though the measures were counterbalanced), both within the same session, and at Time 1 and Time 2, learning effects could play a significant role in the overall results (Gattol, Sääksjärvi \& Carbon, 2011), especially with subjects who have limited prior experience with the IAT (Greenwald \& Nosek, 2001 apud Gattol, Sääksjärvi \& Carbon, 2011). Since 42 participants were first year graduates, and a further 17 were undergraduates in fields different from psychology, it is safe to assume that they previously completed less than 2 IATs.

\section{Limits and future directions}

One significant and major limit of the current research is the fact that it did not measure actual ISE using the IRAP. As stated above, the IAT may not be the best measure to test the actual ISE, and future research should try to simply replicate Remue et al. (2013)'s original findings. In addition, one further limitation is that it is a non-experimental correlational study.

As such, causal conclusions cannot be drawn, and more specifically, the direction of effects can't be determined. Given that depressive symptoms at Time 1 were associated with both standard ISE at Time $2(r=-0.24, \mathrm{p}<.05)$ and actual ISE at Time $2(r=-0.28, \mathrm{p}<.05)$, it would be interesting to see if this trend continues in a third session, which would seem to give weight to the Scar Model described earlier.

One further possible limit of the current study is given by the undergraduate sample used. Since the average depression is low, a possible basement effect could be viewed as a reason for some of the insignificant results.
Finally, another limitation is that both the classical and the modified version of the IAT showed low reliability coefficients in terms of split-half reliability and test-retest reliability Despite the fact that low reliability is a typical issue found with many implicit measures (Lane, Banaji, Nosek \& Greenwald, 2007), the low reliability reduces the correlation of the observed variables and diminishes statistical power.

In conclusion, the present study showed that the only reliable measure for current and future depressive symptoms is the ESE, while neither type of ISE seems to predict depression. The associative measure may not be adequate in predicting depression, but rather the focus should be on propositional (explicit) measures. Nevertheless, depression might later predict both types of ISE, giving weight to the Scar Model of depression. Future research is needed in order to address both the limitations of the present study and to further investigate its findings.

\section{References}

Bar-Anan, Y., \& Nosek, B. A. (2014). A comparative investigation of seven indirect attitude measures. Behavior research methods, 46(3), 668-688. doi:10.3758/s13428013-0410-6

Barnes-Holmes, D., Barnes-Holmes, Y., Power, P., Hayden, E., Milne, R., \& Stewart, I. (2006). Do you really know what you believe? Developing the Implicit Relational Assessment Procedure (IRAP) as a direct measure of implicit beliefs. The Irish Psychologist, 32(7), 169-177.

Bosson, J. K., Swann Jr, W. B., \& Pennebaker, J. W. (2000). Stalking the perfect measure of implicit self-esteem: The blind men and the elephant revisited?. Journal of personality and social psychology,79(4), 631-643. http://dx.doi.org/10.1037/0022-3514.79.4.631

Creemers, D. H., Scholte, R. H., Engels, R. C., Prinstein, M. J., \& Wiers, R. W. (2013). Damaged self-esteem is associated with internalizing problems. Frontiers in psychology, 4, 152. https://dx.doi.org/ 10.3389/fpsyg.2013.00152

De Jong, P. J., Sportel, B. E., De Hullu, E., \& Nauta, M. H. (2012). Co-occurrence of social anxiety and depression symptoms in adolescence: differential links with implicit and explicit self-esteem?. Psychological medicine, 42(03), 475-484. https://doi.org/10.1017/S0033291711001358

De Raedt, R., Schacht, R., Franck, E., \& De Houwer, J. (2006). Self-esteem and depression revisited: Implicit positive self-esteem in depressed patients? Behaviour Research and Therapy, 44(7), 1017-1028. http://dx.doi.org/10.1016/j.brat.2005.08.003

Franck, E., De Raedt, R., \& De Houwer, J. (2007). Implicit but not explicit self-esteem predicts future depressive symptomatology. Behaviour Research and Therapy, 45 (10), 2448-2455. http://dx.doi.org/10.1016/j.brat.2007.01.008

Gattol, V., Sääksjärvi, M., \& Carbon, C. C. (2011). Extending the implicit association test (IAT): assessing consumer attitudes based on multi-dimensional implicit associations. PLoS one, 6(1), e15849.

Gawronski, B., \& Bodenhausen, G. V. (2006). Associative and propositional processes in evaluation: An integrative review of implicit and explicit attitude change. Psychological Bulletin, 132 (5), 692-731. http://dx.doi.org/10.1037/0033-2909.132.5.692

Gawronski, B., \& Bodenhausen, G. V. (2007). Unraveling the processes underlying evaluation: Attitudes from the perspective of the APE Model. Social Cognition, 25 (5), 687-717. doi: 10.1521/soco.2007.25.5.687

Gawronski, B., \& Bodenhausen, G. V. (2011). The associative-propositional evaluation model: Theory, 
evidence, and open questions. In Olson, J.M., \& Zanna, M.P., (Ed). Advances in Experimental Social Psychology, 44, 59-127.

Golijani-Moghaddam, N., Hart, A., \& Dawson, D. L. (2013). The implicit relational assessment procedure: Emerging reliability and validity data. Journal of Contextual Behavioral Science, 2(3), 105-119. http://dx.doi.org/10.1016/j.jcbs.2013.05.002

Greenwald, A. G., \& Farnham, S. D. (2000). Using the implicit association test to measure self-esteem and selfconcept. Journal of personality and social psychology, 79(6), 1022-1038. http://dx.doi.org/10.1037/0022-3514.79.6.1022

Greenwald, A. G., McGhee, D. E., \& Schwartz, J. L. (1998). Measuring individual differences in implicit cognition: the implicit association test. Journal of personality and social psychology, 74(6), 1464-1480.

Greenwald, A. G., Nosek, B. A., \& Banaji, M. R. (2003). Understanding and using the implicit association test: I. An improved scoring algorithm. Journal of personality and social psychology, 85(2), 197-216. http://dx.doi.org/10.1037/0022-3514.85.2.197

Haeffel, G. J., Abramson, L. Y., Brazy, P. C., Shah, J. Y., Teachman, B. A., \& Nosek, B. A. (2007). Explicit and implicit cognition: A preliminary test of a dual-process theory of cognitive vulnerability to depression. Behaviour research and therapy, 45(6), 1155-1167. http://dx.doi.org/10.1016/j.brat.2006.09.003

Hardeveld, F., Spijker, J., De Graaf, R., Nolen, W. A., \& Beekman, A. T. F. (2013). Recurrence of major depressive disorder and its predictors in the general population: results from The Netherlands Mental Health Survey and Incidence Study (NEMESIS). Psychological medicine, 43(01), 39-48.

http://dx.doi.org/10.1016/j.jad.2012.11.008

Hofmann, W., Gawronski, B., Gschwendner, T., Le, H., \& Schmitt, M. (2005). A meta-analysis on the correlation between the implicit association test and explicit selfreport measure. Personality and Social Psychology Bulletin, 31(10), 1369-1385. http://dx. doi.org/10.1177/0146167205275613.

Kessler, R. C., Berglund, P., Demler, O., Jin, R., Merikangas, K. R., \& Walters, E. E. (2005). Lifetime prevalence and age-of-onset distributions of DSM-IV disorders in the National Comorbidity Survey Replication. Archives of general psychiatry, 62(6), 593-602. https://dx.doi.org/10.1001/archpsyc.62.6.593

Lane, K. A., Banaji, M. R., Nosek, B. A., \& Greenwald, A. G. (2007). Understanding and using the implicit association test: IV. In Wittenbrink \& Schwarz (Ed.). Implicit measures of attitudes (pp. 59-102). New York: Guilford Press.

Lemmens, L. H., Roefs, A., Arntz, A., van Teeseling, H. C., Peeters, F., \& Huibers, M. J. (2014). The value of an implicit self-associative measure specific to core beliefs of depression. Journal of behavior therapy and experimental psychiatry, 45(1), 196-202.

https://dx.doi.org/10.1016/j.jbtep.2013.10.006

Parikh, S. V., \& Lam, R. W. (2001). Clinical guidelines for the treatment of depressive disorders, I. Definitions, prevalence, and health burden. Canadian journal of psychiatry. Revue canadienne de psychiatrie, 46, 13S-20S.

Perugini, M., Richetin, J., \& Zogmaister, C. (2012). The formation of implicit and explicit attitudes for neutral and valenced stimuli using the self. Learning and Motivation, 43(3), 135-143. https://doi.org/10.1016/j.lmot.2012.02.002

Remue, J., De Houwer, J., Barnes-Holmes, D., Vanderhasselt, M. A., \& De Raedt, R. (2013). Self-esteem revisited: Performance on the implicit relational assessment procedure as a measure of self-versus ideal self-related cognitions in dysphoria. Cognition \& emotion, 27(8), 1441-1449.

https://dx.doi.org/10.1080/02699931.2013.786681

Remue, J., Hughes, S., De Houwer, J., \& De Raedt, R. (2014). To be or want to be: disentangling the role of actual versus ideal self in implicit self-esteem. PloS one, 9(9), e108837. https://dx.doi.org/10.1371/journal.pone.0108837

Roefs, A., Huijding, J., Smulders, F. T., MacLeod, C. M., de Jong, P. J., Wiers, R. W., \& Jansen, A. (2011). Implicit measures of association in psychopathology research. Psychological bulletin, 137(1), 149-193. http://dx.doi.org/10.1037/a0021729

Rosenberg, M. (1965). Society and the adolescent self-image. Princeton, NJ: Princeton University Press.

Sobocki, P., Jönsson, B., Angst, J., \& Rehnberg, C. (2006). Cost of depression in Europe. The journal of mental health policy and economics, 9(2), 87-98.

Sowislo, J. F., \& Orth, U. (2013). Does low self-esteem predict depression and anxiety? A meta-analysis of longitudinal studies. Psychological Bulletin, 139(1), 213240. http://dx.doi.org/10.1037/a0028931

Spitzer, R. L., Kroenke, K., Williams, J. B., \& Patient Health Questionnaire Primary Care Study Group. (1999). Validation and utility of a self-report version of PRIMEMD: the PHQ primary care study. Journal of the American Medical Association, 282(18), 1737-1744. doi:10.1001/jama.282.18.1737

Steinberg, J. A. (2006). Implicit and Explicit Self-Esteem Level and Reactivity as Predictors of Depression (Unpublished doctoral dissertation). Temple University, Philadelphia.

Steinberg, J. A., Karpinski, A., \& Alloy, L. B. (2007). The exploration of implicit aspects of self-esteem in vulnerability-stress models of depression. Self and Identity, 6(2-3), 101-117. http://dx.doi.org/10.1080/15298860601118884

Wittchen, H. U., Nelson, C. B., \& Lachner, G. (1998). Prevalence of mental disorders and psychosocial impairments in adolescents and young adults. Psychological medicine, 28(01), 109-126. 